\title{
DESAIN DAN IMPLEMENTASI MEDIA PEMBELAJARAN BERBASIS MOBILE LEARNING MENGGUNAKAN MOODLE MOBILE APP
}

\author{
Agariadne Dwinggo Samala ${ }^{\left.1^{*}\right)}$, Bayu Ramadhani Fajri' ${ }^{2)}$, Fadhli Ranuharja ${ }^{3)}$ \\ 1,2,3 Program Studi Pendidikan Teknik Informatika, Universitas Negeri Padang \\ Jl. Prof. Dr. Hamka, Kampus UNP Air Tawar, Padang 25171. Telp. (0751) 7055644, 445118 \\ e-mail: agariadne@ft.unp.ac.id ${ }^{1}$, bayurf@unp.ac.id ${ }^{2}$, fadhliranu@ft.unp.ac.id ${ }^{3}$
}

\begin{abstract}
The purpose of this study is to produce instructional media of ICT guidance based on Mobile Learning using Moodle Mobile App that is valid, practical, and effective. This type of research is Research and Development $(R \& D)$. The development model used is the ADDIE model. The experimental method used Intact-Group Comparison. The sample was students of class X at SMA Negeri 1 Sungai Geringging. The instrument was validation questionnaire to measure validity, response questionnaires to measure the practice, and post-test questions of multiple choice to measure the effectiveness of developed media. The results showed that media declared valid by the validator assessment, and practically use by teachers and learners. Percentage of classical completeness at experiment group reached 87,5\%, and 12,5\% for classical incompleteness. While the control group reached 25\% for classical completeness, and 75\% for classical incompleteness. It means that ICT guidance media based on Mobile Learning using Moodle Mobile App is "valid, practically, and effective" to use in ICT guidance learning process
\end{abstract}

Keywords: Learning Media, ICT, ADDIE, Mobile Learning, Moodle Mobile App.

\section{INTISARI}

Tujuan penelitian ini dilakukan adalah untuk menghasilkan sebuah media pembelajaran bimbingan TIK berbasis Mobile Learning menggunakan Moodle Mobile App yang valid, praktis, dan efektif. Jenis penelitian ini Research and Development (R\&D). Model pengembangan yang digunakan adalah model ADDIE. Metode eksperimen menggunakan Intact-Group Comparison. Subjek penelitian adalah peserta didik kelas X SMA Negeri 1 Sungai Geringging. Instrumen penelitian berupa lembar validasi untuk mengukur validitas, angket respon untuk mengukur praktikalitas, dan soal post-test untuk mengukur efektivitas. Hasil penelitian menunjukan bahwa media dinyatakan valid berdasarkan penilaian validator, dan praktis untuk digunakan oleh guru dan peserta didik. Kelompok eksperimen mencapai 87,5\% untuk ketuntasan klasikal, dan 12,5\% untuk ketidaktuntasan klasikal. Sedangkan kelompok kontrol mencapai $25 \%$ persentase ketuntasan klasikal mencapai dan $75 \%$ untuk ketidaktuntasan klasikal. Maka dapat dimaknai bahwa media pembelajaran bimbingan TIK berbasis Mobile Learning menggunakan Moodle Mobile App "valid, praktis, dan efektif" digunakan dalam proses pembelajaran bimbingan TIK.

Kata Kunci: Media Pembelajaran, TIK, ADDIE, Mobile Learning, Moodle Mobile App.

\section{PENDAHULUAN}

Teknologi Informasi dan Komunikasi (TIK) adalah mata pelajaran wajib dalam kurikulum 2006 kemudian TIK dihapus sebagai mata pelajaran dalam kurikulum 2013. Padahal dalam penerapan kurikulum 2013, guru dan peserta didik dituntut untuk lebih kreatif dan inovatif dalam proses pembelajaran mengikuti perkembangan ilmu pengetahuan dan tekologi masa kini.

Menurut Permendikbud Nomor 45 Tahun 2015 Tentang Perubahan Atas Permendikbud Nomor 68 Tahun 2014 Tentang Peran Guru
Teknologi Informasi dan Komunikasi (TIK) dan Guru Keterampilan Komputer dan Pengelolaan Informasi (KPPI) dalam Implementasi Kurikulum 2013 menyatakan bahwa peran guru TIK dan guru KKPI adalah memberikan bimbingan TIK kepada peserta didik, memberikan fasilitasi TIK sesama guru, dan tenaga kependidikan. Mata pelajaran TIK tidak lagi diberikan dalam jam pelajaran sekolah melainkan diberikan melalui Bimbingan TIK (BTIK) di luar jam pelajaran sekolah.

Berdasarkan pasal 4 dalam Permendikbud Nomor 45 Tahun 2015 dijelaskan pelaksanaan melalui Bimbingan TIK (BTIK) di luar jam 
pelajaran sekolah. Berdasarkan pasal 4 dalam Permendikbud Nomor 45 Tahun 2015 dijelaskan pelaksanaan pembelajaran BTIK dilaksanakan secara klasikal dan individual oleh guru TIK kepada peserta didik.[5]

Pembelajaran TIK yang bergeser menjadi BTIK membuat peran guru mata pelajaran wajib TIK beralih menjadi guru pembimbing BTIK. Pelaksanaan BTIK juga dilaksanakan setelah selesai jam pelajaran di sekolah, sehingga peserta didik cenderung enggan mengikuti pembelajaran BTIK, padahal kemampuan untuk menguasai TIK adalah sebuah keharusan untuk bisa mendorong kemajuan bangsa dalam era globalisasi menghadapi tantangan global di abad 21, mengingat perkembangan ilmu pengetahuan dan teknologi yang semakin pesat.

SMA Negeri 1 Sungai Geringging merupakan salah satu lembaga pendidikan formal atau Sekolah Menengah Atas Negeri yang ada di Kabupaten Padang Pariaman, Jln. Durian Lilin, Kecamatan Sungai Geringging, Sumatera Barat, Indonesia. Kurikulum yang digunakan adalah Kurikulum Tingkaat Satuan Pendidikan (KTSP) dan K13 (Kurikulum 2013). Untuk kelas X menggunakan kurikulum pembelajaran terbaru yaitu Kurikulum 2013, sedangkan untuk kelas XI dan kelas XII masih menggunakan KTSP.

Berdasarkan pengamatan di lapangan, Ada beberapa permasalahan yang dihadapi guru TIK sebagai guru pembimbing BTIK di SMA Negeri 1 Sungai Geringging, diantaranya adalah keterbatasan alokasi waktu dan tempat dalam pelaksanaan pembelajaran BTIK. Pembelajaran BTIK diberikan satu kali dalam seminggu dan satu jam saja di luar jam pelajaran di sekolah. Akibat dari keterbatasan waktu dalam pembelajaran BTIK ini tentu menyebabkan keterbatasan materi bimbingan BTIK yang diberikan kepada peserta didik sehingga kebutuhan peserta didik kurang terpenuhi. Kemudian guru pembimbing BTIK hanya mengandalkan buku cetak sebagai media pembelajaran sehingga kurangnya inovasi dalam penggunaan media pembelajaran ini membuat peserta didik kurang tertarik dan pasif saat mengikuti BTIK. Masalah yang lain adalah peserta didik mengalami kesulitan dalam berkomunikasi langsung atau melaksanakan pembelajaran BTIK secara individual dengan guru pembimbing BTIK, begitu juga dengan guru pembimbing BTIK masih belum mampu melaksanakan pembelajaran BTIK secara individual mengingat media yang digunakan hanya buku cetak sehingga pembelajaran hanya mengandalkan pembelajaran klasikal atau tatap muka saja. Maka dapat disimpulkan bahwa pelaksanaan pembelajaran BTIK di SMA Negeri 1 Sungai Geringging belum optimal.

Berdasarkan permasalahan di atas maka sangat penting adanya media pembelajaran BTIK yang dapat memberikan kemudahan bagi peserta didik maupun guru pembimbing BTIK dalam melaksanakan pembelajaran BTIK, karena media pembelajaran merupakan salah satu komponen yang sangat penting dalam komunikasi, interaksi, dan penyampaian materi. Media pembelajaran tentu sebaiknya mengarah pada pembelajaran abad 21 yaitu harus mampu mengikuti kemajuan teknologi yang serba digital yang memberikan kemudahan, dan kenyamanan. Salah satunya penggunaan teknologi mobile dan internet. Dengan kemampuan bisa diakses oleh berbagai platform, kini internet menjadi pilihan utama dalam berkomunikasi.

Pada transportasi saja misalnya terjadi pergeseran dari transportasi konvensional ke transportasi online dengan memanfaatkan teknologi mobile dan internet sebagai medianya. Selain itu, kehadiran toko online seperti tokopedia, bukalapak, dan lazada dengan memanfaatkan teknologi mobile dan internet mampu menghubungkan antara penjual dan pembeli dalam tranksaksi jual beli secara digital. Untuk itu teknologi menjadi salah satu hal yang tidak boleh diabaikan. Begitu halnya pada sektor pendidikan perlu untuk terus berinovasi, harus berani berubah, beradaptasi mengikuti perkembangan teknologi agar tidak ketinggalan zaman, meskipun tidak mudah namun bukan berarti tidak mungkin. Karena perubahan merupakan sebuah keharusan bukan lagi sebuah pilihan. Pergeseran teknologi lama yang serba fisik ke teknologi digital menjadi hal yang tidak bisa dielakkan, dengan hadirnya media online yang bisa menjembatani interaksi dosen dengan mahasiswa di perguruan tinggi, juga guru dengan siswa atau peserta didik di sekolah, maka menyediakan pembelajaran online atau daring melalui jaringan internet memang sudah waktunya.

Teknologi mobile dan internet sangat penting untuk dapat dimanfaatkan sebagai media dalam pembelajaran BTIK. Salah satunya adalah media pembelajaran menggunakan Moodle Mobile App yang menggunakan konsep pembelajaran mobile learning. Sehingga pembelajaran BTIK tidak lagi tatap muka saja tetapi dapat dilakukan dalam proses pembelajaran jarak jauh. Selain itu peserta didik dan guru pembimbing BTIK dapat melaksanakan pembelajaran BTIK kapanpun, dan dimanapun selama terkoneksi dalam jaringan internet, kemudian materi yang selalu tersedia 24 jam dapat dimanfaatkan, dan dibaca oleh peserta didik baik secara online maupun offline, sehingga media ini diharapkan dapat menunjang 
terlaksananya pembelajaran BTIK yang lebih optimal, serta tercapainya proses pembelajaran. BTIK secara klasikal dan individual yang dapat memfasilitasi kebutuhan peserta didik.

\section{Media Pembelajaran}

Media pembelajaran adalah perantara yang membawa pesan atau informasi bertujuan instruksional atau mengandung maksud-maksud pengajaran antara sumber dan penerima.[5]

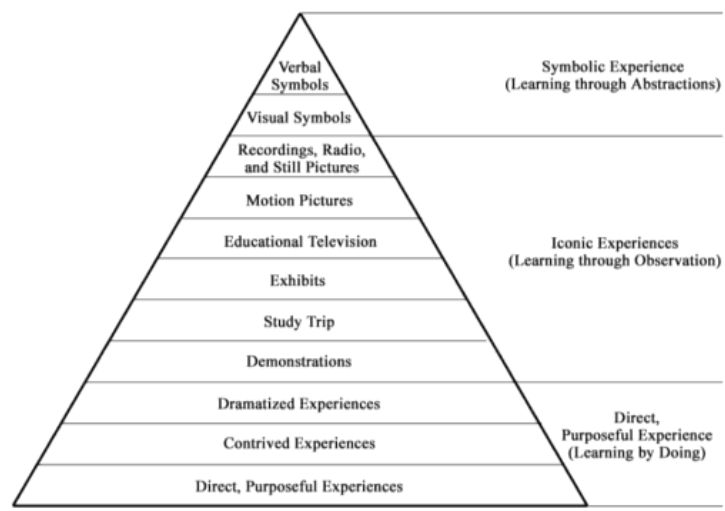

Gambar 1. Dale's Cone of Experience (1969)

Media pembelajaran adalah sebuah alat yang berfungsi dan digunakan untuk menyampaikan pesan pembelajaran. Salah satu gambaran yang paling banyak dijadikan acuan sebagai landasan teori penggunaan media dalam proses belajar adalah Dale's Cone of Experience (Kerucut Pengalaman Dale). [3]

Edgar dale melakukan klasifikasi pengalaman menurut tingkatan, dari yang paling konkrit ke yang paling abstrak, yaitu (1) pengalaman langsung, (2) pengalaman tiruan, (3) pengalaman dramatisasi, (4) percontohan atau demonstrasi, (5) karyawisata, (6) televisi, (7) gambar hidup, (8) gambar tetap, rekaman, dan radio, (9) lambang visual, (10) lambang kata. Jadi dapat disimpulkan bahwa media pembelajaran adalah semua sarana, segala bentuk alat komunikasi yang dapat digunakan untuk menyampaikan materi pembelajaran antara pendidik dan peserta didik selain itu media juga dapat merangsang pikiran, perasaan, perhatian, dan kemampuan peserta didik sehingga mendorong tercapainya proses pembelajaran yang aktif, inovatif, kreatif, efektif dan menyenangkan.

\section{Website}

Website atau web adalah halaman informasi yang ada di internet, dimana halaman tersebut merupakan kumpulan komponen yang terdiri dari teks, gambar dan atau suara animasi. Website merupakan suatu kesatuan dari berbagai elemen dan halaman yang dibuat sedemikian rupa sehingga informasi yang disampaikan tersusun dan teratur dengan baik. [2]

\section{Mobile Learning}

Mobile learning atau disebut dengan istilah m-learning merupakan pembelajaran bergerak yang memanfaatkan teknologi mobile sehingga peserta didik dapat belajar dimana pun tanpa adanya batasan waktu dan tempat. [6]

\section{Moodle}

Moodle (Modular Object Orientid Dynamic Learning Environment) adalah sebuah proram aplikasi yang dapat merubah sebuah media pembelajaran ke dalam bentuk web, yang merupakan salah satu Learning Management System (LMS) yang cukup popular digunakan oleh banyak institusi pendidikan.[4] LMS ini dapat digunakan ataupun dimodifikasi oleh siapa saja dengan lisensi secara GNU (General Public License).[9]

\section{Bimbingan TIK (BTIK)}

Bimbingan TIK merupakan bentuk baru dari pembelajaran mata pelajaran TIK yang diberikan untuk sekolah menengah atas dan sekolah menengah pertama. Dalam kurikulum 2013, mata pelajaran TIK yang sebelumnya mata pelajaran wajib bergeser menjadi Bimbingan TIK atau BTIK.

Berdasarkan Permendikbud Nomor 45 Tahun 2015 Tentang Perubahan Atas Permendikbud Nomor 68 Tahun 2014 Tentang Peran Guru Teknologi Informasi dan Komunikasi (TIK) dan Guru Keterampilan Komputer dan Pengelolaan Informasi (KPPI) dalam Implementasi Kurikulum 2013 menyatakan bahwa peran guru TIK dan guru KKPI adalah memberikan bimbingan TIK kepada peserta didik, memberikan fasilitasi TIK sesama guru, dan tenaga kependidikan.

\section{Metode}

Jenis metode pengembangan yang digunakan dalam penelitian ini adalah Research and Development $(\mathrm{R} \& \mathrm{D})$. Metode $(\mathrm{R} \& \mathrm{D})$ adalah metode penelitian yang digunakan untuk menghasilkan produk tertentu, dan menguji keefektifan produk tersebut.[7] Penelitian ini mengembangkan media pembelajaran untuk bimbingan TIK berbasis Mobile Learning menggunakan Moodle Mobile App.

Untuk penilaian produk yang dikembangkan dilakukan uji validitas oleh ahli media dan ahli materi, kemudian uji praktikalitas berupa angket respon guru pembimbing BTIK dan peserta didik, sedangkan untuk uji keefektifan 
menggunakan metode eksperimen yaitu IntactGroup Comparison. Pada desain ini terdapat satu kelompok yang digunakan untuk penelitian, tetapi dibagi dua, yaitu setengah kelompok untuk eksperimen (yang diberi perlakuan) dan setengah untuk kelompok kontrol (yang tidak diberi perlakuan). [7]

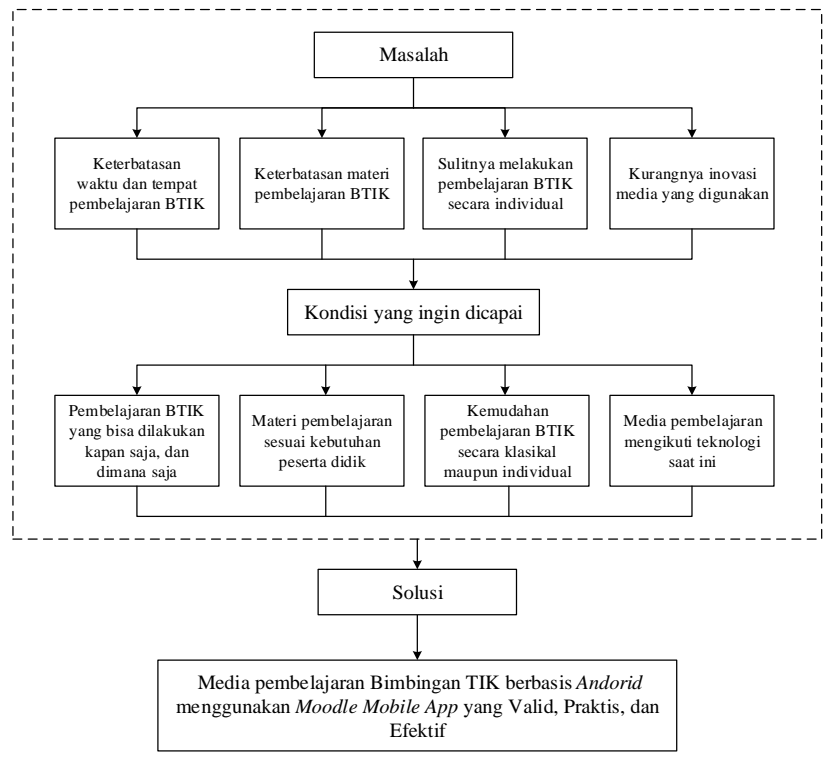

Gambar 2. Kerangka Konseptual

\section{Model Pengembangan}

Model pengembangan yang digunakan adalah Model ADDIE. Model ADDIE memiliki tahapan yang sistematis, dan lebih rasional yaitu terdiri dari lima tahap: Analysis, Design, Development, Implementation, Evaluation seperti pada Gambar 3 dan Gambar 4.

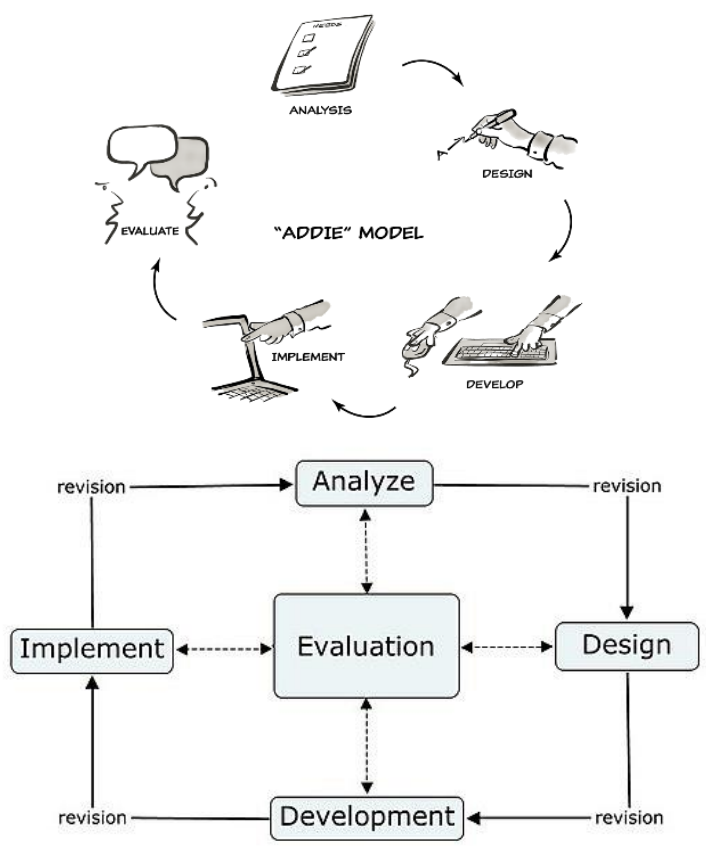

Gambar 3. Model Pengembangan ADDIE

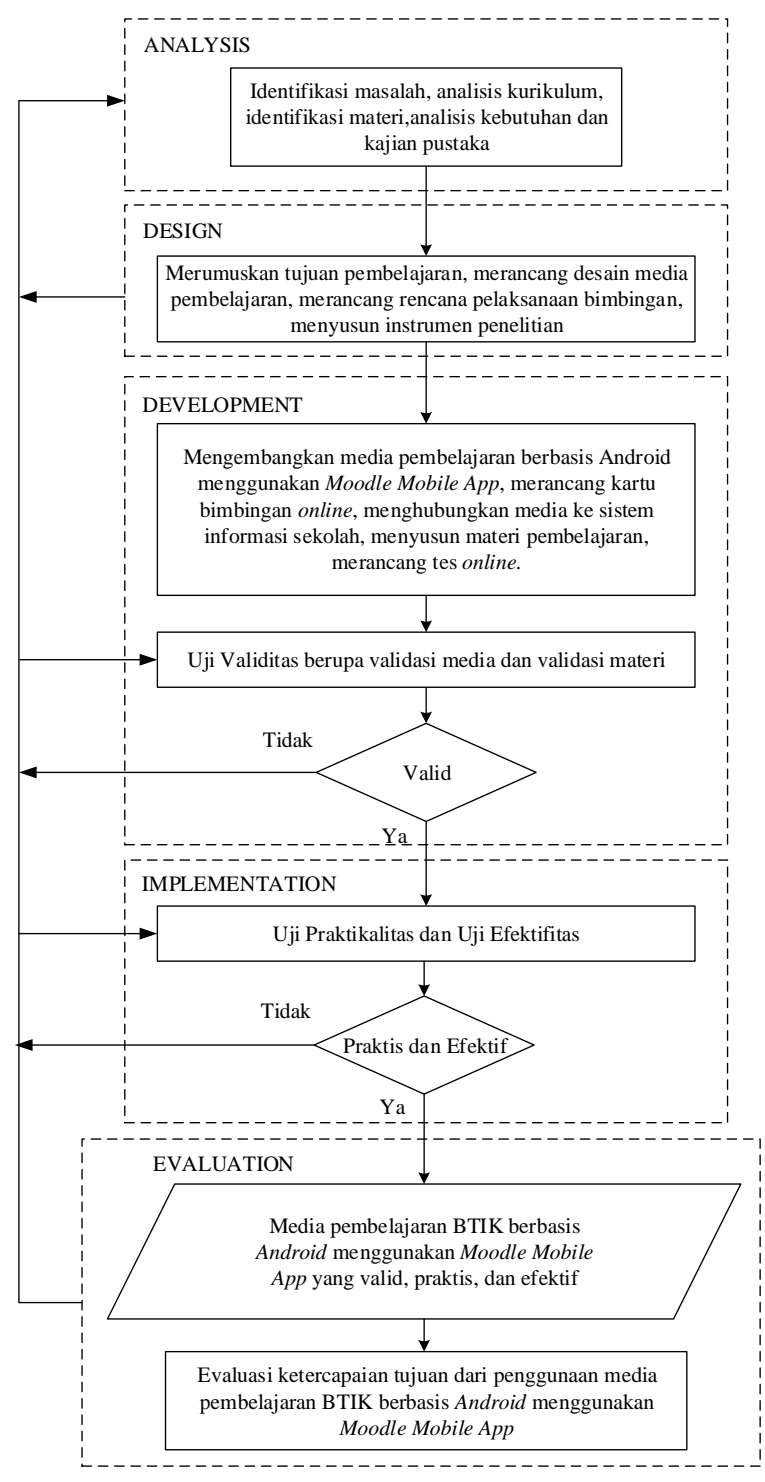

Gambar 4. Prosedur Pengembangan

\section{Subjek Penelitian}

Subjek ujicoba pengembangan media pembelajaran BTIK ini adalah peserta didik kelas X di SMA Negeri 1 Sungai Geringging sebanyak 32 orang kemudian dibagi menjadi dua kelompok yaitu 16 orang untuk kelompok eksperimen dan 16 orang untuk kelompok kontrol. Untuk sampel ujicoba yang diambil menggunakan teknik Purposive Sample. Purposive Sample adalah teknik memilih sampel dengan didasarkan pertimbanganpertimbangan tertentu. Dengan pertimbangan dapat memudahkan peneliti dalam menjelajahi objek atau situasi yang diteliti.

\section{Jenis Data}

Jenis data pada penelitian ini adalah data primer yang terdiri dari data kualitatif dan data kuantitatif. Data primer adalah data yang diperoleh langsung dari sumbernya. Data kuantitatif diperoleh dari instrumen validasi, instrumen 
praktikalitas, dan instrumen efektivitas. Sedangkan data kualitatif diperoleh dari saran dan masukan dari responden.

\section{Instrumen Penelitian}

Instrumen validitas yang digunakan untuk pengumpulan data validitas berupa angket validasi ahli media dan angket validasi ahli materi, Instrumen pengumpulan data praktikalitas berupa angket respon guru pembimbing dan peserta didik, dan Instrumen pengumpulan data efektivitas berupa hasil tes ujian yang valid dan reliabel.

\section{Teknik Analisis Data}

\section{Analisis Validitas}

Data validasi media pembelajaran diperoleh dari para ahli (expert judgement) yaitu oleh validator dari ahli media dan ahli materi yang memberikan masukan - masukan, kemudian masukan-masukan ini dianalisis dan digunakan dalam rangka perbaikan media pembelajaran yang dikembangkan. Analisis validasi media pembelajaran berbasis web menggunakan langkahlangkah berikut:

a. Menentukan kriteria skor jawaban sebagai berikut: $5=$ sangat baik, $4=$ baik, $3=$ cukup baik, 2 = kurang baik, $1=$ tidak baik.

b. Pemberian nilai kevalidan dengan rumus Aiken's:

$$
V=\sum s /[n(c-1)]
$$

Untuk menentukan tingkat kevalidan rentang angka $\mathrm{V}$ yang didapat akan diperoleh antara 0 sampai 1,00 sehingga untuk rentang $\geq 0,667$ dapat diinterprestasikan sebagai koefisien $\mathrm{V}$ yang cukup tinggi, sehingga bisa dikategorikan bahwa kategori validitasnya berada dalam kategori "valid" [8].

\section{Analisis Praktikalitas}

Data praktikalitas media pembelajaran diperoleh dari angket respon guru dan angket respon peserta didik terhadap media pembelajaran BTIK berbasis mobile learning menggunakan Moodle Mobile App yang digunakan. Adapun analisis data praktikalitas media pembelajaran berbasis web menggunakan langkah-langkah berikut:

a. Menentukan kriteria skor jawaban menggunakan skala likert $5=$ sangat setuju, 4 $=$ setuju, $3=$ kurang setuju, $2=$ tidak setuju, 1 $=$ sangat tidak setuju

b. Menjumlahkan nilai seluruh aspek yang dinilai c. Menghitung persentase praktikalitas dengan menggunakan rumus:

$$
P=\frac{\sum f}{N} \times 100 \%
$$

d. Menentukan kategori praktikalitas menggunakan penilaian skala lima dengan acuan pengubahan skor menurut kriteria kategori kepraktisan sebagai berikut:

Tabel 1. Kategori Praktikalitas

\begin{tabular}{ccc}
\hline No & Persentase & Kategori \\
\hline 1 & $90 \%-100 \%$ & Sangat Praktis \\
\hline 2 & $80 \%-90 \%$ & Praktis \\
\hline 3 & $65 \%-80 \%$ & Cukup Praktis \\
\hline 4 & $55 \%-65 \%$ & Kurang Praktis \\
\hline 5 & $0 \%-55 \%$ & Tidak Praktis \\
\hline
\end{tabular}

Sumber: Modifikasi dari Purwanto (2009)

\section{Analisis Efektivitas}

Dalam pengujian efektivitas ini terdapat satu kelompok subjek penelitian yang kemudian dibagi menjadi dua kelompok yaitu kelompok kontrol dan kelompok eksperimen kemudian diberikan tes ujian (post-test). Dari data yang diperoleh, kemudian dilakukan perbandingan hasil post-test kelompok eksperimen dan hasil post-test kelompok kontrol. Media pembelajaran dikatakan efektif apa efektif apabila hasil post-test kelompok eksperimen lebih tinggi daripada hasil post-test kelompok kontrol. Tahap pelaksanaan:

a. Menyusun rencana pelaksanaan bimbingan TIK (BTIK)

b. Memberikan bimbingan menggunakan media pembelajaran BTIK berbasis mobile learning menggunakan Moodle Mobile App pada kelompok eksperimen dan tanpa menggunakan media pembelajaran BTIK berbasis mobile learning menggunakan Moodle Mobile App pada kelompok kontrol.

c. Memberikan post-test berupa tes ujian pada kelompok kelas eksperimen dan kelompok kontrol.

d. Diperoleh hasil post-test dari kelompok kontrol dan kelompok eksperimen, dan dianalisis dengan menggunakan rumus sebagai berikut:

$$
K B=\frac{T}{T_{t}} \times 100
$$

e. Diperoleh data ketuntasan belajar peserta didik, selanjutnya peserta tes dinyatakan 
tuntas jika mencapai $\mathrm{KKM} \geq 75$ seperti yang telah ditetapkan oleh sekolah.

f. Langkah selanjutnya yaitu menentukan ketuntasan klasikal, menentukan nilai ketuntasan klasikal dapat dihitung menggunakan rumus sebagai berikut:

Ketuntasan Klasikal $=\frac{\text { banyak peserta tes tuntas }}{\text { Jumlah peserta tes }} \times 100 \%$

g. Perbandingan hasil posstest dan persentase ketuntasan klasikal dari kelompok kontrol dan kelompok eksperimen akan menjadi indikator yang menentukan tingkat ketercapaian atau efektivitas dari media yang dikembangkan.

Tabel 2. Kategori Efektivitas

\begin{tabular}{ccc}
\hline No & Persentase & Kategori \\
\hline 1 & $90 \%-100 \%$ & Sangat Efektif \\
\hline 2 & $80 \%-90 \%$ & Efektif \\
\hline 3 & $65 \%-80 \%$ & Cukup Efektif \\
\hline 4 & $55 \%-65 \%$ & Kurang Efektif \\
\hline 5 & $0 \%-55 \%$ & Tidak Efektif \\
\hline
\end{tabular}

Sumber: Modifikasi dari Purwanto (2009)

\section{HASIL DAN PEMBAHASAN}

Media pembelajaran yang dibuat dan dikembangkan dalam penelitian ini berupa sebuah media pembelajaran bimbingan TIK berbasis mobile learning menggunakan Moodle Mobile App seperti pada Gambar 5 adalah tampilan home dari media pembelajaran.

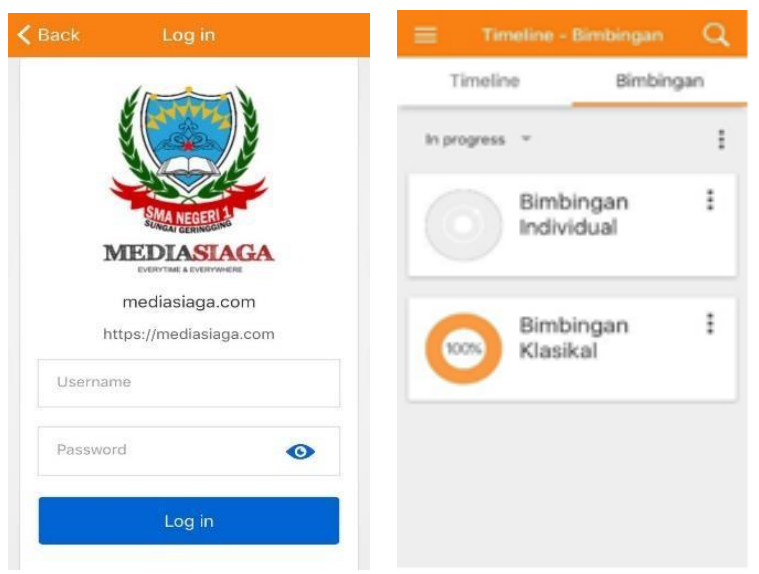

Gambar 5. Tampilan Home

Media ini selain mendukung interaksi dan komunikasi guru pembimbing dengan peserta didik baik secara klasikal dan individual, media juga dijadikan sebagai sumber belajar dimana materi pembelajaran, video tutorial dapat diakses secara online menggunakan jaringan internet maupun secara offline setelah materi di-download menggunakan Moodle Mobile App oleh peserta bimbingan. Media juga memiliki ruang diskusi dan ruang chat antar peserta, maupun dengan guru pembimbing, peserta bimbingan sebagai pengguna media juga dapat mengakses sistem informasi sekolah, kartu bimbingan online, youtube channel, pencarian google bahkan melakukan ujian online dalam satu aplikasi.

Media pembelajaran mobile learning memiliki halaman untuk meilhat kompetensi inti dan dasar juga materi bimbingan TIK berupa file pdf yang bisa diakses tanpa internet dengan syarat sudah didownload minimal sekali melalui aplikasi.
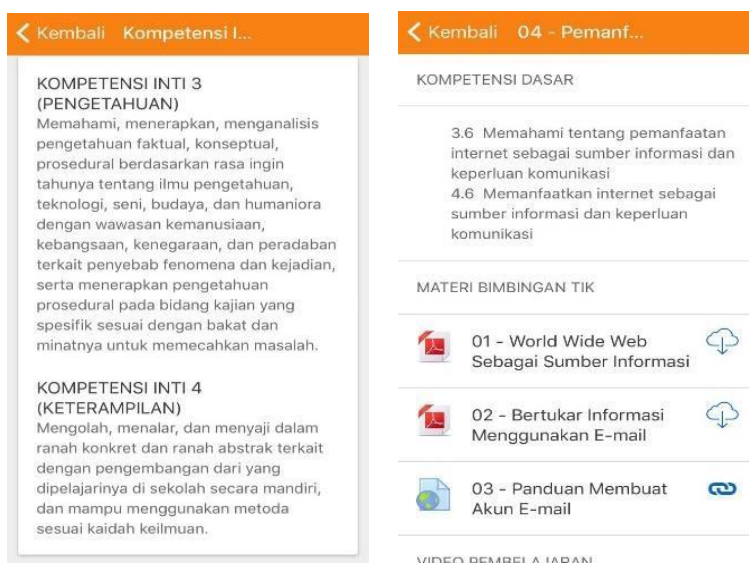

Gambar 6. Penyajian KI dan KD

Proses bimbingan online juga didukung dengan fitur kumpul tugas secara online, selain pesan pribadi juga terdapat saluran komunikasi seperti chating dan ruang diskusi untuk interaktivitas antar pengguna sehingga peserta dapat saling berkomunikasi satu dengan yang lain juga dapat berkomunikasi dengan guru pembimbing melalui aplikasi tersebut seperti yang terlihat pada Gambar 7. Merupakan tampilan ruang diskusi dan halaman chating.

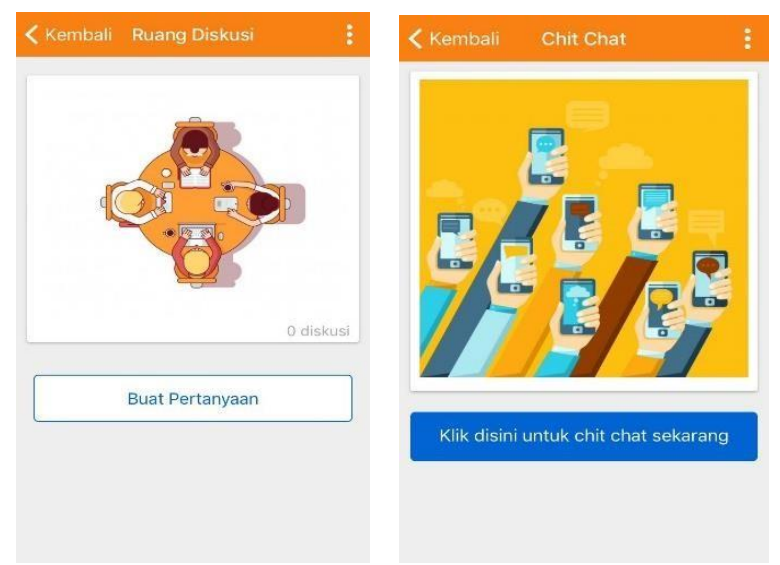

Gambar 7. Tampilan Chat dan Ruang Diskusi 
Tabel 3. Hasil Validasi Media dan Validasi Materi

\begin{tabular}{|c|c|c|c|c|c|c|c|c|c|c|}
\hline \multirow{2}{*}{ No. } & \multirow[t]{2}{*}{ Aspek } & \multirow[t]{2}{*}{ Jumlah Butir Penilaian } & \multicolumn{5}{|c|}{ Total Skor Validator } & \multirow[t]{2}{*}{$\Sigma \mathrm{s}$} & \multirow[t]{2}{*}{ Aiken's V } & \multirow[t]{2}{*}{ Kategori } \\
\hline & & & & V1 & V2 & V3 & V4 & & & \\
\hline 1 & Media & 30 & & 135 & 135 & - & - & 210 & 0,879 & Valid \\
\hline 2 & Materi & 12 & & - & - & 53 & 53 & 82 & 0,861 & Valid \\
\hline \multirow{3}{*}{$\begin{array}{c}\text { Tabel } \\
\text { No. }\end{array}$} & . Hasil Praktik & kalitas Media & \multirow{2}{*}{\multicolumn{5}{|c|}{ Total Skor Validator }} & & & \\
\hline & Aspek & $\begin{array}{l}\text { Jumlah Butir } \\
\text { Penilaian }\end{array}$ & & & & & & $\Sigma \mathrm{f}$ & $\%$ & Kategori \\
\hline & & & $\begin{array}{c}1 \\
(\mathrm{TS})\end{array}$ & $\begin{array}{c}2 \\
(\mathrm{CS}) \\
\end{array}$ & $\begin{array}{c}3 \\
(\mathrm{KS}) \\
\end{array}$ & $\begin{array}{c}4 \\
(\mathrm{~S}) \\
\end{array}$ & $\begin{array}{c}5 \\
(\mathrm{SS}) \\
\end{array}$ & & & \\
\hline 1 & Guru & 20 & 0 & 0 & 0 & 8 & 12 & 92 & 92,00 & Sangat Praktis \\
\hline \multirow[t]{2}{*}{2} & Peserta Didik & 20 & 1 & 1 & 33 & 137 & 148 & 1390 & 86,68 & Praktis \\
\hline & Rata-rata & & & & & & & & 89,44 & Praktis \\
\hline
\end{tabular}

Berdasarkan hasil perhitungan lembar validasi media, maka diperoleh nilai akhir validitas untuk media yaitu 0,879>0,667 dan diperoleh nilai akhir validitas untuk materi yaitu $0,861>0,667$, artinya media dan materi dinyatakan dalam kategori "valid".

Untuk persentase praktikalitas media secara keseluruhan dapat dihitung dari rata-rata persentase praktikalitas yang diperoleh dari angket respon guru dan angket respon peserta didik yaitu sebesar $89,44 \%$. Nilai persentase praktikalitas berada pada rentang $80 \%$ - 90\%, sehingga praktikalitas media secara keseluruhan dinyatakan "praktis" untuk digunakan guru dan peserta didik.

Perbandingan hasil post-test kelompok kontrol dan kelompok eksperimen juga dapat diketahui dari histogram hasil SPSS 23 pada Gambar 7. bahwa pada kelompok kontrol ada peserta yang mencapai nilai 60 , dua peserta pada kelompok kontrol mencapai nilai 80 dan tidak ada satupun peserta dari kelompok kontrol yang mencapai nilai post-test diatas 80 . Sementara, pada Gambar 8. dapat diketahui bahwa ada peserta dari kelompok eksperimen yang mencapai nilai 84 , nilai 88 , dan nilai 92, dan tidak ada satupun peserta dari kelompok eksperimen yang memperoleh nilai posttest dibawah 65.

Tabel 5. Hasil Post-test Kontrol dan Eksperimen

\begin{tabular}{ccc}
\hline Nilai & Kontrol & Eksperimen \\
\hline Varians & $\mathbf{3 4 , 0 7}$ & $\mathbf{3 7 , 2 7}$ \\
\hline S. Dev & $\mathbf{5 , 8 4}$ & $\mathbf{6 , 1 0}$ \\
\hline Max & $\mathbf{8 0}$ & $\mathbf{9 2}$ \\
\hline Min & $\mathbf{6 0}$ & $\mathbf{6 8}$ \\
\hline $\mathrm{x}$ & $\mathbf{7 0 , 2 5}$ & $\mathbf{8 0 , 2 5}$ \\
\hline $\mathrm{N}$ & $\mathbf{1 6}$ & $\mathbf{1 6}$ \\
\hline
\end{tabular}

Rata-rata hasil post-test keseluruhan dari kelompok kontrol didapatkan 70,25 dan kelompok eksperimen adalah 80,25.

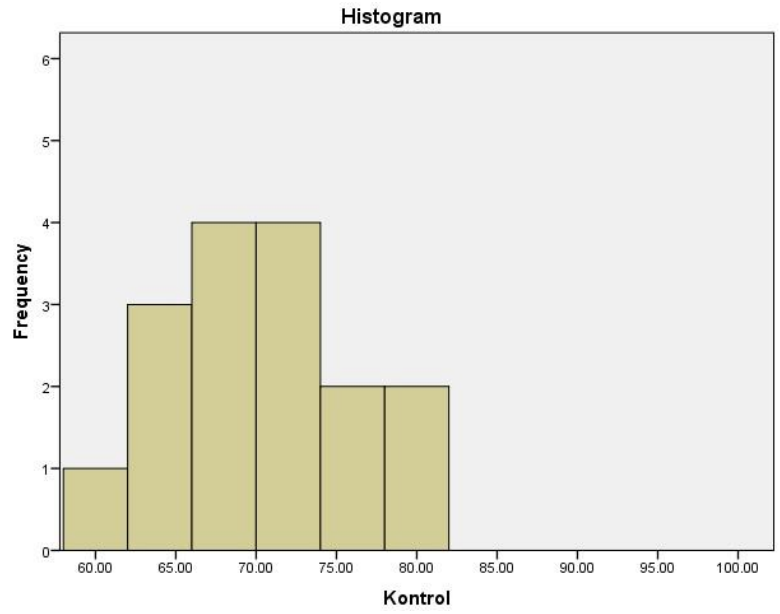

Gambar 7. Histogram Hasil Post-test Kelompok Kontrol

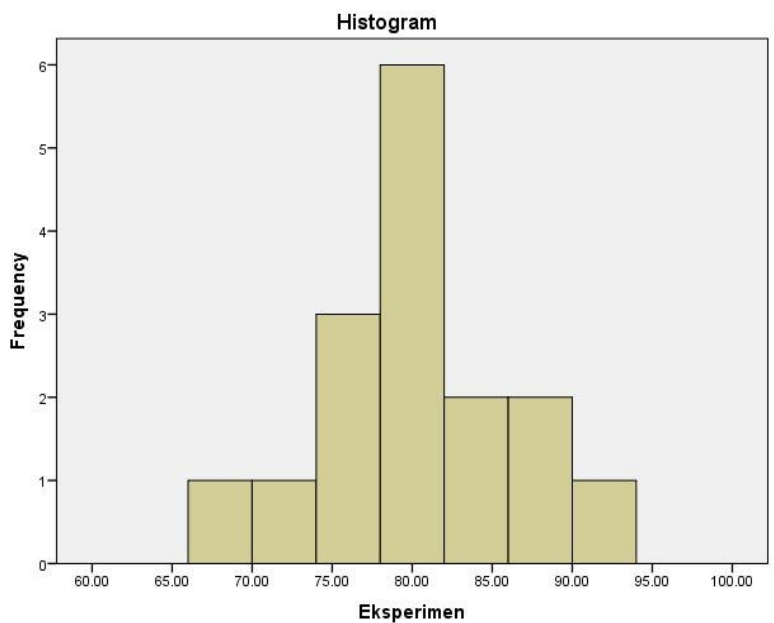

Gambar 8. Histogram Hasil Post-test Kelompok

Pada Tabel 5. dapat dimaknai hasil posttest kelompok eksperimen lebih baik daripada kelompok kontrol, sehingga dapat diperoleh kesimpulan bahwa penggunaan media pembelajaran bimbingan TIK berbasis mobile learning menggunakan Moodle Mobile App memberikan pengaruh yang positif, baik dan efektif mampu membantu mengatasi kesulitan dalam proses bimbingan dan meningkatkan hasil belajar. 


\section{DAFTAR PUSTAKA}

[1]A. Arsyad, Media Pembelajaran. Jakarta, PT. Rajagrafindo Persada, 2014.

[2] A. Kadir, Pengenalan Sistem Informasi Edisi Revisi. Yogyakarta, Andi, 2013.

[3]E. Dale, Audiovisual methods in teaching, 3rd ed. New York, Dryden Press, 1969.

[4]H. D. Surjono, Membangun Course E-Learning Berbasis Edisi Kedua. Yogyakarta, UNY Press, 2013.

[5] Kemendikbud, Permendikbud Nomor 45 Tentang Perubahan Atas Peraturan Menteri Pendidikan dan Kebudayaan Republik Indonesia Nomor 68 Tahun 2014 Tentang Peran Guru Teknologi Informasi dan Komunikasi dan Guru Keterampilan Komputer dan Pengelolaan Informasi Dalam Implementa. Indonesia, 2015.

[6]O. Claire, "Guidelines for Learning/Teaching/Tutoring in Mobile Environment," 2003.

[7]S. Azwar, Reliabiltas dan Validitas. Edisi 4. Yogyakarta, Pustaka Belajar, 2012.

[8]Sugiyono, Metode Penelitian Kuantitatif, Kualitatif dan R\&D. Bandung, Alfabeta, 2010.

[9] Moodle. 2019. (https://moodle.org) diakses pada tanggal 22 Maret 2019. 